\title{
Effect of Motivation on Job Satisfaction of Selected Sales Representatives
}

\section{Ogunnaike, Olaleke Oluseye}

\author{
Department of Business Management, \\ Covenant University, Ota, Ogun State, Nigeria \\ E-mail: olaleke.ogunnaike@covenantuniversity.edu.ng
}

Akinbola, Olufemi Amos

Department of Business Management, Covenant University, Ota, Ogun State, Nigeria. E-mail: femi.akinbola@covenantuniversity.edu.ng

Ojo, Olugbenga Abiola

Faculty of Business and Law, Leeds University Business school Leeds Metropolitan University, United Kingdom

Email: a.ojo3432@students.leedsmet.ac.uk

\section{Doi:10.5901/jesr.2014.v4n1p197}

\section{Abstract}

\begin{abstract}
Sales managers are concerned with motivation of individual salespersons as well as motivation of the entire sales force. A well motivated salesperson is expected to be satisfied with his or her job. Consequently, he or she is expected to render satisfying services to the customers. This study was able to examine intrinsic motivation and extrinsic motivation separately and their effects on job satisfaction. Copies of questionnaire were distributed randomly to the sales representatives of the sampled four service firms for the study. Two hypotheses were developed and were subjected to regression analysis. It was discovered that both intrinsic and extrinsic motivations are crucial to enriching the job satisfaction of the sales representatives. The study makes useful recommendations which entrepreneurs and sales managers will find very useful if implemented.
\end{abstract}

Keywords: intrinsic motivation, extrinsic motivation, job satisfaction.

\section{Introduction}

Motivation is the psychological feature that arouses a person to action toward a desired goal and elicits controls and sustains certain goal directed behaviour. Bedeian, (1993) defines motivation as "an internal drive to satisfy an unsatisfied need and the will to accomplish". Motivation can also be seen as that internal drive that causes an individual to decide to take action. Employee motivation can be seen as an intrinsic enthusiasm and drive to accomplish activities related to work. It is also the level of energy, commitment and creativity that a company or organizations' puts in to perform their job. Employee motivation is particularly relevant because an appropriate employee motivation system can grant tangible benefits to any organisation. "Employee motivation is one of the policies of managers to increase effectual job management amongst employees in organizations" (Shadare et al, 2009). It is very important for management or managers to find ways to motivate their employees. In situations where employees realize that their opinions and contributions are considered and valued, it gives them a sense of belongingness which can motivate them. When employees are motivated, they are more likely to perform better at their jobs. As an old saying goes, you can take a horse to the water but you cannot force it to drink; it would only drink if its thirsty or wants to, so is it for people. People do what they want to or if they are motivated to do so. They are either driven internally or externally.

"Job satisfaction is a pleasurable or positive emotional state resulting from the appraisal of one's job experiences"'. Locke (1976) defined job satisfaction as "the measurement of one's total feelings and attitudes towards one's job". It is also "any combination of psychological, physiological, and environmental circumstances that causes a person truthfully to say, 'I am satisfied with my job'. The perceived job satisfaction brings about a positive feeling and encouragement. It is necessary for employees to be satisfied with their jobs and the conditions of their jobs. Employee job satisfaction plays 
an important role in the profit making of an organisation. If there is dissatisfaction, it could lead to poor service or quality, turnovers, absenteeism, low productivity and so on.

The main aim of this study is to find out the relationship between employee motivation and job satisfaction in an organizational set-up. The objectives of the study are enumerated below:

1. To determine if intrinsic motivation has any significant effect on job satisfaction.

2. To determine if extrinsic motivation has any significant effect on job satisfaction.

\section{Literature Review}

The term motivation is derived from the Latin term 'movere', which means 'to move' (Baron, Henley, McGibbon and McCarthy, 2002). Motivation refers to "the reasons underlying behaviour" (Guay et al., 2010). Campbell and Pritchard (1976, p.78) defined motivation as "a label for the determinants of the choice to initiate effort on a certain task, the choice to expend a certain amount of effort, and the choice to persist in expending effort over a period of time". Motivation, therefore, closes the satisfaction-performance loop, and has to do with a set of interrelated factors that explain an individual's behaviour, holding constant the variables controlled or influenced by management, as well as by individual skills, abilities and knowledge (Campbell \& Pritchard, 1976). Spector (2003) saw motivation as an internal state that induces a person to engage in particular behaviours, and held that motivation may be viewed from two angles. To Nelson and Quick (2003), motivation is the process of arousing and sustaining goal-directed behaviour. Gouws (1995) defined motivation as an inner wish or urge that originates with an individual, either consciously or unconsciously, to complete a task successfully because it is enjoyable, and not necessarily for what will be received in return. In an age where retaining talent is crucial to their prosperity, companies realise that they need to do a better job at letting employees know that their work matters, by stepping up employee recognition (Clarke, 2001).

\subsection{Intrinsic and extrinsic motivation}

An individual's goals are related to his or her reasons for engaging with tasks. Goals can be subdivided into mastery goals (which can be compared with intrinsic values) and performance goals (which can be compared with extrinsic motivation) (Broussard \& Garrison, 2004). Beach (1980) recognised intrinsic motivation as related to the job content and as that which occurs when people perform an activity from which they derive satisfaction from simply engaging in the activity itself.

Intrinsic motivation is defined as the doing of an activity for its inherent satisfactions rather than for some separable consequence. The intrinsic rewards refer to the inherent features of work and characteristics associated with the task itself, for instance the capacity to confer to workers a sense of achievement, interest, responsibility or accomplishment (Kalleberg 1977). Valuation of this dimension thus reflects the workers' desire to be stimulated and challenged by the job and to be able to exercise acquired skills at work. According to previous research, intrinsic rewards have important implications for workers' overall satisfaction at work and desire to commit to their job (Broussard and Garrison, 2004); (Guay et al 2010).

Thus, the rewards coming from the intrinsic aspects of work often serve as the most important motivational factors for social workers who interact with clients, by providing help and assistance, hoping to achieve change and improvement in clients' lives. In addition to the altruistic motives, studies have demonstrated the importance of selfdirected motives related to personal interests and quest for working tasks that individuals find meaningful and engaging (Jensen 2003). This type of motivation is from within an individual. When intrinsically motivated a person is moved to act for the fun or challenge entailed rather than because of external pressures, or rewards. Although, in one sense, intrinsic motivation exists within individuals, in another sense intrinsic motivation exists in the relation between individuals and activities. People are intrinsically motivated for some activities and not others, and not everyone is intrinsically motivated for any particular task. With reference to employees' intrinsic motivation dimension, task enrichment theory holds that a person's motivation is increased by his or her experience of meaningful and enriching job content (Hackman \& Oldham, 1976; Tyagi, 1985). As Deci et al. (1999) observe, "Intrinsic motivation energizes and sustains activities through the spontaneous satisfactions inherent in effective volitional action. It is manifest in behaviours such as play, exploration, and challenge seeking that people often do for external rewards". The notion of intrinsic motivation is closely related to intrinsic value. Intrinsic motivation refers to motivation that is animated by personal enjoyment, interest, or pleasure, and is usually contrasted with extrinsic motivation, which is manipulated by reinforcement contingencies (Guay et al., 2010). Some factors that can be looked at to see if employees are internally motivated include interest, autonomy and flexibility 
amongst others.

Extrinsic motivation is a construct that pertains whenever an activity is done in order to attain some separable outcome. Extrinsic motivation deals with external environment i.e. what the organisation has to offer. The extrinsic rewards often refer to job characteristics that are external to the tasks themselves, providing benefits or rewards like pay, job security and recourse adequacy (Herzberg 1968). The extrinsic dimension also include the more symbolic rewards in terms of client recognition and public approval and the social support in relationship with co-workers and whether the job permits chances for the workers to take personal interests in each other as colleges. Valuation of this dimension reflects a workers desire for the satisfaction of social needs from the work activity.

Extrinsic motivation thus contrasts with intrinsic motivation. For example, a student who does his homework only because he fears parental sanctions for not doing it is extrinsically motivated because he is doing the work in order to attain the separable outcome of avoiding sanctions. Similarly, a student who does the work because she personally believes it is valuable for her chosen career is also extrinsically motivated because she too is doing it for its instrumental value rather than finding it interesting. Extrinsic motivation can occur by the provision of rewards, which can be either tangible (e.g., money, grades, privileges, etc.) or intangible (e.g., praise).

For employees to be externally motivated there are some factors that should be noted. Firstly, material rewards. The extrinsic dimension of employee motivation is concerned with the premium placed on material reward at work. Material or extrinsic, rewards are those provided by the organisation that are tangible and visible to others (Bellenger et al., 1984). Research on issues surrounding material reward for work performance reported a significant positive correlation between the extent to which people are motivated by financial reward and their level of satisfaction with their work (Agho et al., 1993; Bellenger et al., 1984; Hoole \& Vermeulen, 2003) added that pay appeared to be significantly less important to more senior employees, who valued higher-order rewards more highly, for example, recognition and respect from colleagues. As with praise and recognition, material reward represents a visible means by which an employee's contribution towards the interests of the company, and as such also his or her value to the organisation, may be affirmed. For many, it also represents affirmation of their self-worth, and successful pursuit of their self-actualisation aspirations.

Secondly, progression involves an employee having a sense of moving forward. When employees know there are positions ahead of them that need to be filled, it acts as a source of motivation for them.

\subsection{Job satisfaction}

Job satisfaction is defined as the individuals' attitudes toward the various aspects of their jobs as well as towards the job in general. Locke (1969) defines job satisfaction as the pleasurable emotional state that results from the appraisal of one's job as achieving or facilitating the achievement of one's job values. The perceived job satisfaction creates positive feelings among employees, which in turn, represents positive emotional reaction towards desire for empowerment. Locke further argues that the satisfaction is achieved when one realizes one's important job values provided these are congruent with or help to fulfil one's basic needs.

The values or conditions conducive to job satisfaction are; mentally challenging work which the individual can cope successfully, personal interest in the work itself, work that is not too physically tiring, rewards for performance that are just, informative and in line with the individual's personal aspirations, working conditions that are compatible with the individual's physical needs and that facilitate the accomplishment of his work, high self esteem on the part of the employee and agents in the work place who help the employee to attain job values such as interesting work, pay and promotions, whose basic values are similar to his own, and who minimize role conflict and ambiguity. Job satisfaction is a multi-faceted construct (Churchill, Ford, \& Walker, 1974; Comer, Machleit, \& Lagace, 1989).

\section{Research Methods}

This study is explanatory in nature and relies on a field survey to collect the required data. For the purpose of this study, the survey research design was used and questionnaire was designed to get data pertaining to the research questions and objectives stated. The research population is the total number of sales representatives in four selected service firms in Lagos, Nigeria. With aid of Yard's formular a total number of 138 respondents constituted the sample size for this study. 


\subsection{The research tool:}

The required data was collected by means of a self-administered questionnaire, which was developed for this purpose. The questionnaire consists of four sections. Section 1 considered the biography of the respondents. Section 2 examines the level of internal motivation practice of the four service firms. Section 3 measured the extent to which external motivation practices are being engaged by the firms. The fourth section relates to job satisfaction of the staff. Job satisfaction in this case was restricted to physical working conditions and job equipment, career opportunities, social matters, remuneration, fringe benefits and personnel policy. The data obtained from this questionnaire were collated for the analysis. The reliability of the research instrument was examined by Cronbach alpha and found to be 0.719 , which is considered acceptable for this research. Regression analysis was conducted on the data with aid of a statistical package (SPSS).

\section{Hypotheses Testing and Discussion of Results}

- Hypothesis 1

- Ho: intrinsic motivation does not have any significant effect on job satisfaction

- $H_{1}$ : intrinsic motivation has significant effects on job satisfaction

- Hypothesis 2

- $H_{0}$ : extrinsic motivation does not have any significant effect on job satisfaction

- $\mathrm{H}_{1}$ : extrinsic motivation has significant effects on job satisfaction

\subsection{Hypothesis 1}

\subsubsection{Regression}

Table 1a: Regression model summary $f$

\begin{tabular}{|c|c|c|c|c|}
\hline Mode & R & R Square & Adjusted R Square & Std. Error of the Estimate \\
\hline 1 & $.373^{\mathrm{a}}$ & .139 & .122 & .97760723 \\
\hline
\end{tabular}

a. Predictors: (Constant), my organisation has clear rules and systems for doing tasks, i am usually closely supervised in the job i do

Source: Field Survey, 2013.

Interpretation of Result: The model summary table shows how much of the variance in the dependent variable (job satisfaction) is explained by the model. In this case the R square is .139 if expressed by a percentage will be $13.9 \%$. This means that our model explains $13.9 \%$ of the variance in job satisfaction.

Table 1b: ANOVA

\begin{tabular}{|c|c|c|c|c|c|}
\hline Model & Sum of Squares & Df & Mean Square & F & Sig. \\
\hline Regression & 15.419 & 2 & 7.709 & 8.067 & $.001^{\mathrm{a}}$ \\
1 Residual & 95.572 & 100 & .956 & & \\
Total & 110.990 & 102 & & & \\
\hline
\end{tabular}

a. Predictors: (Constant), my organisation has clear rules and systems for doing tasks, i am usually closely supervised in the job i do

b. Dependent Variable: i am satisfied with the physical working conditions and equipments of this organization

Source: Field Survey, 2013.

Interpretation of Result. The ANOVA table shows the assessment of the statistical significance (sig $=0.001)$, in which the F-value is equal to 8.067 , and the significant level is less than 0.05 therefore we reject the null hypothesis. So we can 
conclude that intrinsic motivation is useful for predicting job satisfaction.

Table 1c: Coefficients for hypothesis two

\begin{tabular}{|l|c|c|c|c|c|}
\hline \multicolumn{1}{|c|}{ Model } & Unstandardized Coefficients & Standardized Coefficients & \\
\cline { 2 - 6 } & $\mathrm{B}$ & Std. Error & Beta & $\mathrm{T}$ & Sig. \\
\hline (Constant) & 2.222 & .464 & & 4.791 & .000 \\
1 i am usually closely supervised in the job i do & .152 & .104 & .145 & 1.452 \\
my organisation has clear rules and systems for doing tasks & .313 & .107 & .293 & 2.925 & .004 \\
\hline
\end{tabular}

a. Dependent Variable: i Job satisfaction

Source: Field Survey, 2013.

The table seeks to explain which of the variables is making a statistically significant unique contribution to the model looking at the sig column in the table; intrinsic motivation has significant effects on job satisfaction. Intrinsic motivation made a unique and statistical significant contribution to the model.

Decision; Hence, we reject the null hypothesis. The implication of this result is intrinsic motivation has significant effects on job satisfaction.

\subsection{Hypothesis 2}

$\mathrm{H}_{0}$ : extrinsic motivation does not have any significant effect on job satisfaction

$\mathrm{H}_{1}$ : extrinsic motivation has significant effects on job satisfaction

\subsubsection{Regression}

Table 2a: Regression model summary

\begin{tabular}{|c|c|c|c|c|}
\hline Model & $\mathrm{R}$ & $\mathrm{R}$ Square & Adjusted R Square & Std. Error of the Estimate \\
\hline 1 & $.279^{\mathrm{a}}$ & .078 & .069 & .64213632 \\
\hline
\end{tabular}

a. Predictors: (Constant), i have a good prospect for advancement in the organization

Source: Field Survey, 2013.

Interpretation of Result. The model summary table shows how much of the variance in the dependent variable (job satisfaction) is explained by the model. In this case the R square is .078 if expressed by a percentage will be $7.8 \%$. This means that our model explains $7.8 \%$ of the variance in job satisfaction.

Table 2b: ANOVA

\begin{tabular}{|l|c|c|c|c|c|}
\hline \multicolumn{1}{|c|}{ Model } & Sum of Squares & Df & Mean Square & F & Sig. \\
\hline Regression & 3.607 & 1 & 3.607 & 8.748 & $.004^{\mathrm{a}}$ \\
1 Residual & 42.883 & 104 & .412 & & \\
$\quad$ Total & 46.491 & 105 & & & \\
\hline
\end{tabular}

a. Predictors: (Constant), i have a good prospect for advancement in the organization

b. Dependent Variable: i have positive relationship with my colleagues and supervisors

Source: Field Survey, 2013.

Interpretation of Result: The ANOVA table shows the assessment of the statistical significance (sig $=0.004)$, in which the F-value is equal to 8.748 , and less than or equal to 0.004 , therefore we reject the null hypothesis. So we can conclude that extrinsic motivation is useful for predicting job satisfaction. 
Table 2c: Coefficients

\begin{tabular}{|c|c|c|c|c|c|}
\hline \multirow{2}{*}{ Model } & \multicolumn{2}{|c|}{ Unstandardized Coefficients } & \multirow{2}{*}{\begin{tabular}{|c} 
Standardized Coefficients \\
Beta
\end{tabular}} & \multirow[b]{2}{*}{$\mathrm{T}$} & \multirow[b]{2}{*}{ Sig. } \\
\hline & $\mathrm{B}$ & Std. Error & & & \\
\hline (Constant) & 3.840 & .235 & & 16.368 & .000 \\
\hline${ }^{1}$ i have a good prospect for advancement in the organization & .178 & .060 & .279 & 2.958 & .004 \\
\hline
\end{tabular}

a. Dependent Variable: i have positive relationship with my colleagues and supervisors

Source: Field Survey, 2013.

The table seeks to explain which of the variables is making a statistically significant unique contribution to the model looking at the sig column in the table; it reveals that extrinsic motivation contribute significantly to job satisfaction. This is because it made a unique and statistical significant contribution to the model.

Decision; Hence, we reject the null hypothesis. The implication of this result is that extrinsic motivation has significant effects on job satisfaction.

\section{Discussion of Findings}

The findings of this study are divided into two (2) namely; theoretical findings and empirical findings. The theoretical findings are drawn from the literature review while the empirical findings are derived from the data generated from the field survey.

\subsection{Empirical findings}

The first hypothesis result shows how much of the variance in the dependent variable (job satisfaction) is explained by the model. In this case the R square is .139 if expressed by a percentage will be $13.9 \%$. This means that our model explains $13.9 \%$ of the variance in job satisfaction. It was discovered that intrinsic motivation has significant effect job satisfaction.

It was discovered that there are clear rules and regulations that guide the operations of the organization and that this is one of the effective platforms for promoting intrinsic motivation.

Material reward is one of the indicators of extrinsic motivation that influences job satisfaction significantly.

\section{Conclusion}

The research has been able to achieve the objectives it set out to achieve. There has been a good survey research and the content has been very useful to proffer solutions to the research questions. It is noted from this study that employees are the internal customers that must first be satisfied with their job in order to promote (external) customers' satisfaction. Satisfied employees are most likely going to be productive employees. This study discussed about various means of motivating the employees in order to enhance their job satisfaction and the findings validate the fact that both intrinsic and extrinsic motivations have significant relationship with job satisfaction.

\section{Recommendations}

Based on the findings of the study, the following recommendations were made:

i. Management of organizations should employ various means of motivating their employees in order to improve on job satisfaction.

ii. Job enrichment is essential for stimulating the interest of workers towards their jobs

iii. Organizations must ensure that there is clarity of rules and system of doing tasks within organization. This is because flexibility of operation will be possible and workers will be able to take initiatives where necessary to get the tasks accomplished

iv. Material reward, as one of the extrinsic motivation must be properly managed. Fairness and equity are very essential in the reward system. 
v. There is need for organization to have good promotion policy that will empower the employees for career advancement.

\section{References}

Bedeian A.G. (1993). "Management 3rd edition". New York: Dryden Press

Locke, E.A. (1976). "What is Job Satisfaction?".Organizational Behaviour and Human Performance. 4, pp. 309-336.

Baron, H., Henley, S., McGibbon, A. \& McCarthy, T. (2002). "Motivation questionnaire manual and user's guide".Sussex: Saville and Holdsworth Limited.

Guay, F., Chanal, J., Ratelle, C. F., Marsh, H. W., Larose, S., \& Boivin, M. (2010). "Intrinsic, identified, and controlled types of motivation for school subjects in young elementary school children". British Journal of Educational Psychology, 80(4), 711-735.

Campbell, J.P. \& Pritchard, R.D. (1976). "Motivation theory in industrial and organizational psychology". In M.D. Dunnette (Ed.), Handbook of industrial and organizational psychology (pp.63 - 130). Chicago: Rand McNally.

Gouws, A. (1995). "Die verwantskap tussen motivering en werkstevredenheid van 'n groep inligtingspesialiste (The relationship between motivation and job satisfaction of a group of information specialists)". M.Bib. dissertation, Rand Afrikaans University, Johannesburg.

Nelson, D.L. and Quick, J.C. (2003). "Organizational Behaviour: Foundation, Realities and Challenges (4th ed.)". Australia: Thomson South-Western

Spector, P.E. (2003). "Industrial and organizational psychology - Research and practice (3rd edition)". New York: John Wiley \& Sons, Inc.

Clarke, R.D. (2001). "Well dones shouldn't be rare". Black Enterprise, 32(3), 67-69.

Beach, D.S. (1980). "Personnel: The management of people at work (4th ed.)". New York: Macmillan Publishing Co. Inc.

Broussard, S. C., \& Garrison, M. E. B. (2004). "The relationship between classroom motivation and academic achievement in elementary school-aged children".Family and Consumer Sciences Research Journal, 33(2), 106-120.

Kallberg, A.L., B.F. Reskin, and K. Hudson., (2000). "Bad Jobs in America: Standard and Nonstandard Employment Relations and Job Quality in the United States". American Sociology Review 65(2):256-278.

Hackman, J. Richard \& Oldham, Greg R. (1976). "Motivation Through the Design of Work: Test of a Theory". Organizational Behaviour and Human Performance 16 (2): pp. 250-279.

Deci, E. L., Koestner, R., \& Ryan, R. M. (1999). "A meta-analytic review of experiments examining the effects of extrinsic rewards on intrinsic motivation".Psychological Bulletin, 125(6), 627-668.

Tyagi, P.K. (1985). "Work motivation through the design of salesperson jobs". Journal of Personal Selling and Sales Management, 5(1), $41-52$

Herzberg, Frederick (1968). "One More Time: How Do You Motivate Employees?". Harvard Business Review 46 (1): pp. 53-62.

Agho, A.O., Mueller, C.W. \& Price, J.L. (1993). "Determinants of employee job satisfaction: An empirical test of a causal model". Human Relations, 46(8), $1007-1027$.

Bellenger, D.N., WilcoX, J.B. \& Ingram, T.N. (1984). "An examination of reward preferences for sales managers". Journal of Personal Selling and Sales Management, 4(2), $1-6$.

Hoole, C. \& Vermeulen, L.P. (2003). "Job satisfaction among South African pilots". South African Journal of Industrial Psychology, 29(1), $52-57$.

Churchill, G. A., Jr., Ford, N., \& Walker, O. C., Jr. (1974). "Measuring the job satisfaction of industrial salesmen". Journal of Marketing Research, 11(3), 254-260.

Comer, J. M., Machleit, K. A., \& Lagace, R. R. (1989). "Psychometric assessment of a reduced version of INDSALES". Journal of Business Research, 18(4), 291-302.

Herzberg, Frederick (1966). "Work and the Nature of Man". Cleveland: World Publishing.

Higgins, E. T. (1999). "When do self-discrepancies have specific relations to emotions? The second-generation question of Tangney, Niedenthal, Covert, and Barlow (1998)". Journal of Personality and Social Psychology, 77, 1313-1317

Jung, Kwangho and Kim, Tae-II, (2004). "Comparative Analysis of Job Satisfaction between Public and Private Organization in Korean Labor \& Income Study Data." The Korean Policy Study Review, 12 (3):1-29 
